\title{
Soldiers' physical activity of daily life: a systematic literature review
}

\author{
Christin Schilz ${ }^{1,2} \cdot$ Stefan Sammito ${ }^{2,3}$ (I) \\ Received: 30 December 2020 / Accepted: 27 April 2021 / Published online: 18 May 2021 \\ (C) The Author(s) 2021
}

\begin{abstract}
Purpose High physical fitness and good health are not only essential for the civilian population but also for persons working in physically and psychologically demanding professions, such as armed forces personnel. To date there is no scientific summary of studies dealing with the physical activity of daily life in armed forces personnel, but this is necessary for a targeted intervention. Methods A systematic review was performed in the PubMed database (target date: 24 May 2020), using the search terms "military personnel" and "exercise" or "(physical) activity of daily life" including the assigned MESH words.

Results Seven original papers have focused on the daily physical activity of military personal, and they were all conducted in different countries. The activity of daily life was on average 11,540 steps per day.

Conclusions It could be shown that soldiers performed more physical activity than the civilian population and that the recommended 10,000 steps per day were slightly exceeded on average. However, the number of steps performed was very low in fields of activity with limited physical activity options, such as on board a ship. Altogether, it thus seems that additional healthpromoting physical activity programs are not required for most of the soldiers, but that, in contrast, corresponding offers for physical activity alternatives, e.g., in the form of fitness equipment, are urgently required in specific task areas (e.g., on board ships).
\end{abstract}

Keywords Activity of daily life $\cdot$ Prevention $\cdot$ Military $\cdot$ Health promotion $\cdot$ Army

\section{Introduction}

Physical activity is an essential cornerstone for maintaining and improving one's health status. To achieve this, a high basic physical activity of daily life and specific sports sessions are equally important (Pfeifer and Rütten 2017). The World Health Organization (WHO) recommends regular physical activity in order to minimize the risk of chronic diseases. In this context, even a slight increase in physical activity is important, especially for inactive persons (WHO 2010).

However, it is difficult for many people to integrate this physical activity into their daily lives. In 2016, the share of the world population that was not physically active enough was

Stefan Sammito

stefansammito@bundeswehr.org

1 Department X - Anesthesiology and Intensive Care, Bundeswehr Central Hospital Koblenz, Koblenz, Germany

2 Department of Occupational Medicine, Medical Faculty, Otto von Guericke University, Magdeburg, Germany

3 German Air Force Centre of Aerospace Medicine, Department I 3, Flughafenstraße 1, 51147 Cologne, Germany
27.5\% (Guthold et al. 2018). Worldwide, every third woman and every fourth man perform too little physical activity. According to the WHO, physical inactivity is most distinct in the industrial nations (Guthold et al. 2018). Many people work in sitting positions and travel over long distances by motor vehicle or other means of transport due to increased mobility. In accordance with a study of 2018, German adults sit for seven and a half hours per day on average (Froböse et al. 2018). Every fifth one even spends nine hours or more sitting (Voermans et al. 2016). In 2010, approximately $60 \%$ of the study population achieved the target value of $150 \mathrm{~min}$ of physical activity per week specified by the WHO, but this share decreased to just $43 \%$ of the respondents in 2018 (Froböse et al. 2018). When comparing active and inactive groups of persons, the overall mortality risk can be reduced by 30\% through regular physical activity (WHO 2010; Brown et al. 2012; Warburton et al. 2010). The general mortality risk increases concurrently with the daily sitting duration: From a daily sitting duration of more than $13 \mathrm{~h}$ on, the mortality risk doubles in comparison to persons only sitting for less than 11 hours (Diaz et al. 2017). Moreover, the risk of cardiovascular diseases decreases (Brown et al. 2012; Warburton et al. 2010; Perk et al. 2012) as does the probability of contracting 
diabetes mellitus type II (Warburton et al. 2010) when the amount of physical activity of daily life increases.

High physical fitness and good health are not only essential for the civilian population but also for persons working in physically and psychologically demanding professions, such as armed forces personnel. In order to cope with regular military service at home and abroad in general and with the special requirements of missions abroad in particular, soldiers must have a high fitness level (Sammito and Mayer-Falcke 2017). In this context, regular physical activity of daily life creates a good foundation for basic fitness, which can be enhanced by means of additional general and special taskspecific physical training. Particularly in the context of the introduction of "occupational health management" (Sammito et al. 2015), especially the consideration of physical activity in daily life as a cornerstone for Bundeswehr personnel is gaining importance. So far, however, there has not been any overview of scientifically collected data on this subject.

Therefore, a systematic literature review on studies dealing with physical activity of daily life in armed forces personnel, which have already been conducted, was performed.

\section{Methods}

For this purpose, a systematic review was performed in the PubMed database (target date: 24 May 2020), using the search terms "military personnel" and "exercise" or "(physical) activity of daily life" including the assigned MESH words. Included in the review were studies on physical activity of daily life in military personnel of all nationalities as far as they belonged to the regular military (independent of the Service), and especially the United States Coast Guard as a uniformed Service of the US armed forces, where the number of daily steps or the physical activity of daily life has been recorded. In contrast, studies focusing on police personnel and personnel belonging to technical emergency services, disaster control services, the fire department and civilian coast guards were not included.

The fitness level of the test persons was also included in the systematic review in the form of a surrogate parameter with minor significance. All studies were included, independent of the type of data collection (questionnaire, interview, pedometer measurement or tracking).

The focus of the search lay on cross section surveys. Intervention studies were included, if data on the baseline survey had been indicated separately. Within the scope of the review, articles in German and English were taken into account.

The PubMed review with the above-mentioned search terms resulted in 1219 hits. Following abstract screening, 1203 of these articles were excluded. Of these 1203 articles,
1182 were topically inappropriate, and 21 were not available in English or German.

This resulted in 16 abstracts meeting the inclusion criteria. After completion of the full text screening, nine additional articles were excluded because they did not meet the inclusion and exclusion criteria. The systematic literature review performed yielded seven usable original papers as a result (refer to Fig. 1).

\section{Results}

The seven usable original papers (Table 1) had all been prepared in the armed forces of different branches. The studies included test persons from the Navy (Choi et al. 2010; Tharion et al. 2004) and the Air Force (Scott et al. 2007). In the paper of Schulze et al. (2015), test persons from both the army and the air force had been examined, and in three studies (Aandstad et al. 2016; Nykanen et al. 2019; Wyss et al. 2012), an allocation to the individual Services was not possible due to lacking data. In addition to this, the studies were conducted all in different countries: Germany (Schulze et al. 2015), England (Scott et al. 2007), Finland (Nykanen et al. 2019), Norway (Aandstad et al. 2016), Switzerland (Wyss et al. 2012), South Korea (Choi et al. 2010) and the USA (Tharion et al. 2004). In data collections, active soldiers (four studies (Choi et al. 2010; Schulze et al. 2015; Scott et al. 2007; Tharion et al. 2004)) were preferably examined as compared to recruits (Wyss et al. 2012), soldiers involved in missions abroad (Nykanen et al. 2019), and reservists (Aandstad et al. 2016). The number of test persons varied between 17 (Tharion et al. 2004) and 411 (Aandstad et al. 2016).

In the majority of studies, most of the participants were men. There were exclusively male participants in four studies (Aandstad et al. 2016; Choi et al. 2010; Kinnunen et al. 2012; Nykanen et al. 2019; Wyss et al. 2012). Only one data collection was dominated by female participants (Staudter et al. 2011; Tharion et al. 2004). The average age lay between $20.2 \pm 3.95$ years (Scott et al. 2007) and $33.5 \pm 7.7$ years (Choi et al. 2010).

The data determined with regard to the number of daily steps lay between $2211 \pm 121 \mathrm{steps} /$ day for a submarine crew at sea (Choi et al. 2010) and 11,382 \pm 3174 steps/day for soldiers at an air force training base (Scott et al. 2007).

The study of Choi et al. (2010) yielded the interesting result that age, rank and body mass index (BMI) do not have any significant influence on daily physical activity in contrast to the existence of physical activity options, which are very limited on board a ship, for example. In this context, it must be taken into account, however, that the above study examined test persons in a submarine at sea. In contrast to this result, the study of Schulze et al. (2015) showed an influence of rank on the extent of daily physical activity. 
Fig. 1. Overview of the search algorithm for the systematic literature review

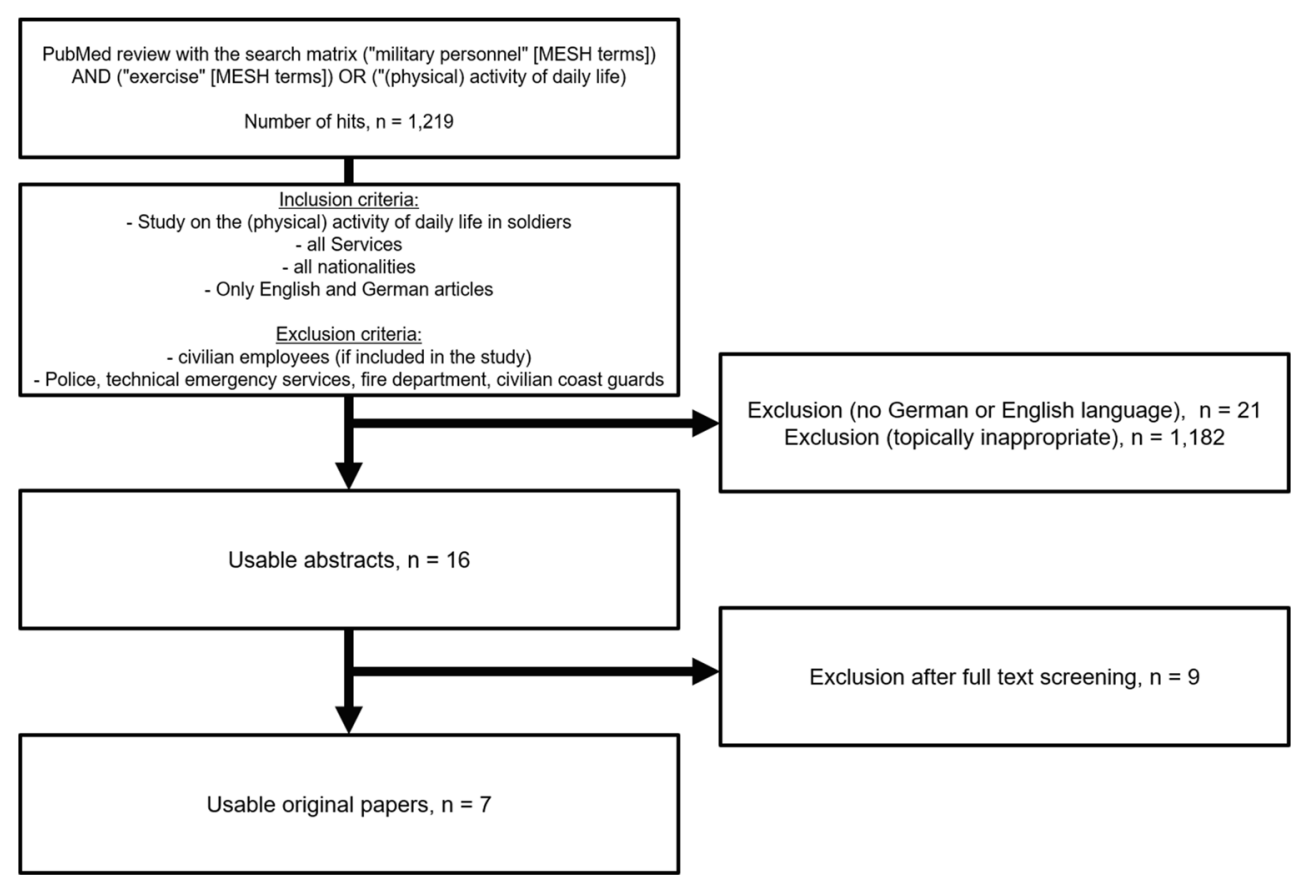

Owing to the great differences in the studies found, the results of the studies will be described individually below.

A data collection regarding physical activity behavior was performed on 411 soldiers of the Norwegian Home Guard. The soldiers had an average BMI of $26.1 \pm 3.7 \mathrm{~kg} / \mathrm{m}^{2}$. The 411 test persons (exclusively men) were subjected to a measurement of the number of steps performed during seven offduty days. The "SenseWear Armband (SWA) $\mathrm{Pro}_{2}$ monitors" pedometer (BodyMedia, Pittsburgh, Pennsylvania) was used for this study. The result of the study was that, on off-duty days, an average physical activity extent of 10,448 steps/day on the weekdays and of 9209 steps/day on the weekend could be determined (Aandstad et al. 2016).

One study was performed on 76 male soldiers of two submarine crews and on an additional 33 male soldiers of a Navy Submarine Command of the South Korean Navy; $79.8 \%$ of the test persons had the rank of petty officer and had been serving in the South Korean Navy for an average of 12.3 years. In $57.8 \%$ of the test persons, the BMI was in the normal range. The age of the participants lay between 22 and 57 years, with an average age of 33.5 years. The measurement of daily steps was recorded by means of "DMC-03" manufactured by Shinwoo Electronics Co. for one month during employment in the submarine and during stationing ashore, respectively. The data collected showed an average amount of 2211 steps per day on board the submarine and of 8181 steps per day during stationing ashore. In this context, age, rank and BMI did not have any significant influence on physical activity of the soldiers in contrast to the limited physical activity options on board the submarine (Choi et al. 2010).
Another data collection examined the daily physical activity of Finnish soldiers (Nykanen et al. 2019) during a sixmonth mission abroad in Lebanon. The participants, who were also exclusively male, were subjected to a three-time determination of the number of steps performed over a period of ten days, respectively, in order to examine the changes that occurred during the deployment period. With regard to the initial first measurement, the test persons performed an average of 9835 steps/day; with the number of daily steps decreasing in the course of the mission abroad.

In the German military, a data collection was performed in the air force and navy, comprising a total of 169 test persons; $84.0 \%$ of the participants were male and had an average BMI of $26.6 \mathrm{~kg} / \mathrm{m}^{2}$. Data collection was effected by means of the "Portable sensor activPAL" pedometer (PAL Technologies, Glasgow, UK), which was worn for seven days without any interruption. The evaluation of the measurement values collected only refers to the on-duty hours and yielded the result of 541 steps per hour for officers, 600 for noncommissioned officers (NCOs), and 724 for team rank during working hours (Schulze et al. 2015). However, a precise indication of the duration of daily working hours cannot be obtained from the study. The authors discussed the theory that soldiers with higher ranks frequently perform executive activities, including a higher share of office work, so that their physical activity decreases.

Another study examined test persons of the Royal Air Force (RAF). This study was performed by means of the "Lifestyles NL-2000" device over a period of two weeks. There were 180 participants in the first week and 139 in the second. With regard to the overall number of test persons, the 


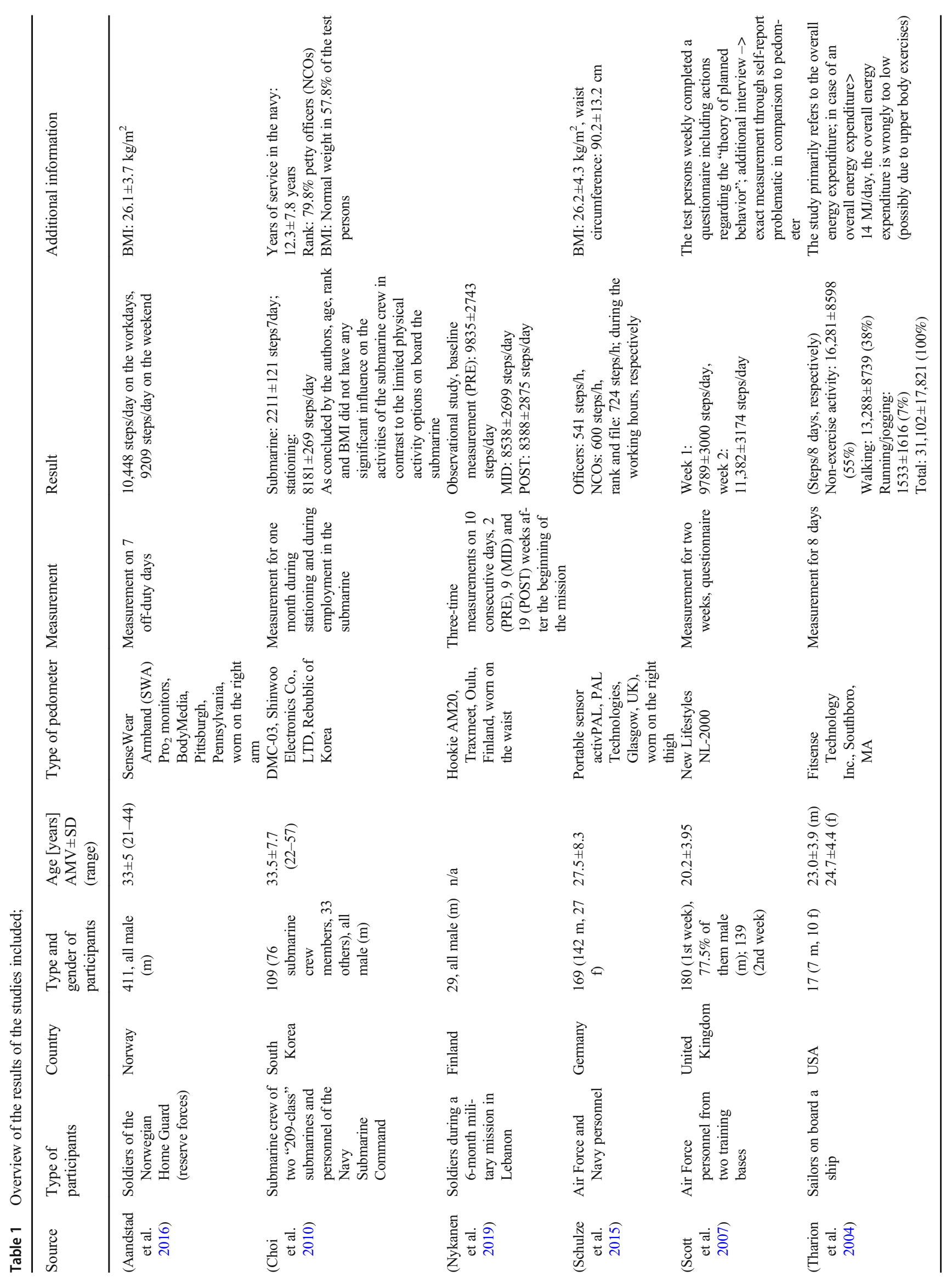




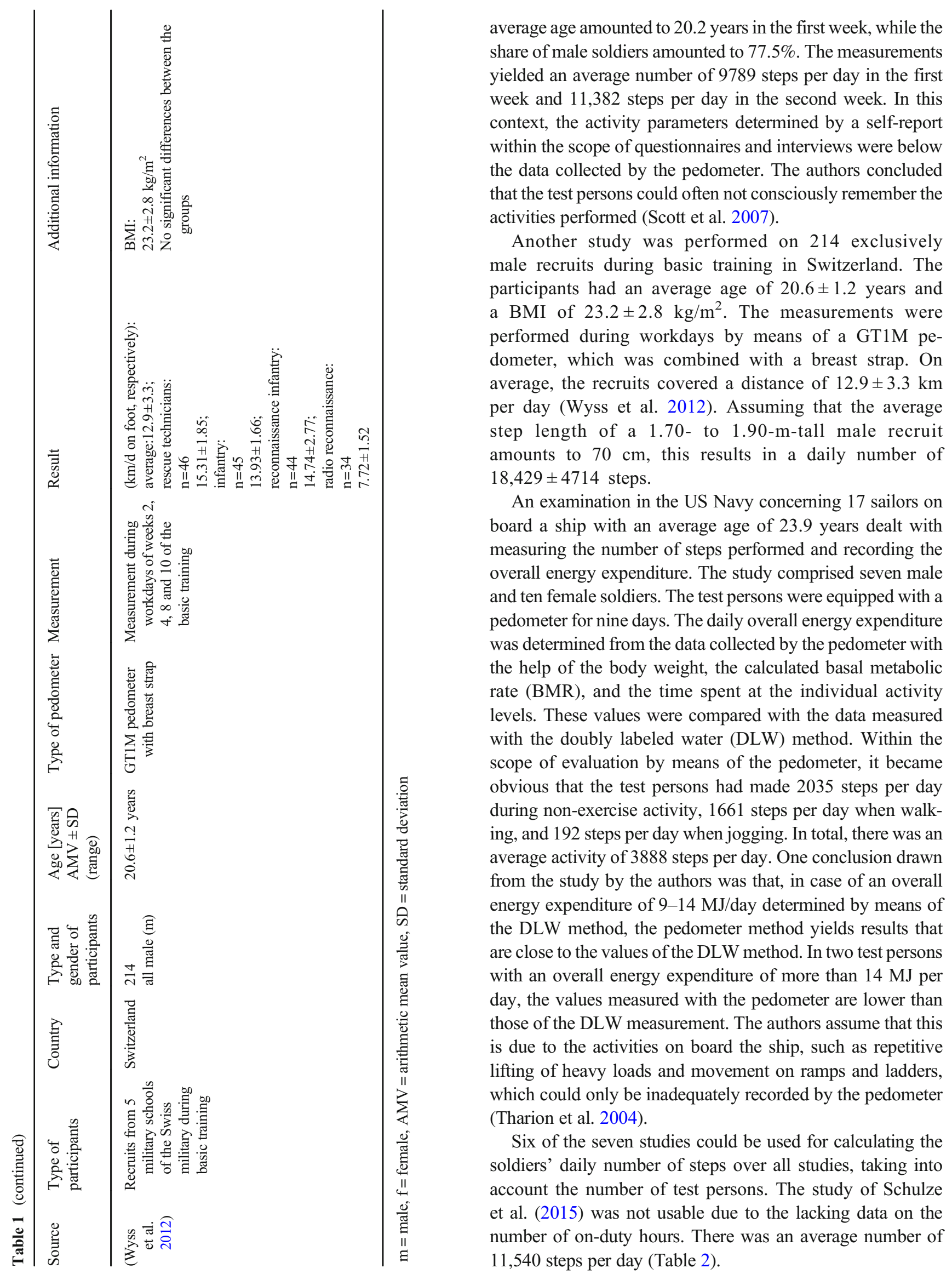


Table 2 Calculation of the average number of steps, taking into account the number of test persons of all usable studies

\begin{tabular}{|c|c|c|c|}
\hline Source & Number of test persons & Measurement of the number of steps & Conversion into steps per day \\
\hline (Aandstad et al. 2016) & 411 & $\begin{array}{l}10,448 \text { steps/day on the workdays } \\
9209 \text { steps/day on the weekend }\end{array}$ & $\begin{array}{l}(10,448 \text { steps } / \text { day } \times 5 \text { days }+9209 \text { steps } / \text { day } \times 2 \text { days }) \\
7 \text { days }=10,094 \text { steps } / \text { day }\end{array}$ \\
\hline$(\text { Choi et al. 2010) })^{1}$ & 109 & 8181 steps/day & \\
\hline$\left(\right.$ Nykanen et al. 2019) ${ }^{2}$ & 40 & 9835 steps/day & \\
\hline$(\text { Scott et al. 2007) })^{3}$ & 180 & 9789 steps/day & \\
\hline (Tharion et al. 2004) & 17 & 31,102 steps $/ 8$ days & $31,102: 8$ days $=3888$ steps $/$ day \\
\hline (Wyss et al. 2012) & 214 & $12.9 \mathrm{~km} /$ day & $12,9 \mathrm{~km} /$ day: $0.0007 \mathrm{~km}^{*}=18,429 \mathrm{steps} /$ day \\
\hline Averaged number of steps & 971 & $11,540 \mathrm{steps} /$ day & \\
\hline
\end{tabular}

${ }^{1}$ The measurements performed during stationing ashore were used for the purpose of comparability with the other studies

2 The measurement values of the baseline measurement were used

3 The measurements of the 1 st week were used

* The assumed step length amounts to $70 \mathrm{~cm}$

$\mathrm{n} / \mathrm{a}=$ Use for evaluation purposes was not possible due to lacking data

\section{Discussion}

In the seven studies recorded by the systematic literature review, the soldiers performed between 2211 and 18,429 \pm 4714 steps per day on average. Taking into account the respective number of test persons in the individual studies, this results in an averaged number of 11,540 steps per day excluding sea travel, which were performed by the soldiers examined. Altogether, there was a broad spectrum of test person collectives within the military from various countries and partly under specific framework conditions (e.g., missions abroad).

In comparison with studies among the civilian population, the soldiers examined in this case performed more physical activity in total. Thus, a study on 717,527 persons in 111 countries showed a physical activity of approximately 4900 steps per day on overall average (Althoff et al. 2017). There was a country-specific spectrum ranging from 6880 steps per day (in Hong Kong) to 3500 steps per day (in Indonesia). In addition, the study showed that men perform more physical activity than women.

Within the scope of prevention, a physical activity extent of 10,000 steps per day is recommended for adults (Tudor-Locke et al. 2011). On average, this value is not achieved by the civilian population (Althoff et al. 2017) and only in individual studies by soldiers (Aandstad et al. 2016; Wyss et al. 2012). Although an average number of 11,540 steps per day could be determined in the calculation over all studies, it must not be overlooked that, under particular framework conditions (e.g., at sea), the number of steps performed by soldiers is significantly lower (cf. (Choi et al. 2010; Tharion et al. 2004). This results in an increased risk of cardiovascular and metabolic diseases, obesity, and low physical fitness as was shown by examinations in the US Navy (Gregg and Jankosky 2012) and on 1383 men of the Brazilian Navy (Costa et al. 2011). During missions abroad, the number of daily steps also seems to decrease over the deployment period (Nykanen et al. 2019). These are military-specific peculiarities that must be taken into account within the scope of preventive medical care at both the behavior level and the ratio level. In this context, corresponding offers could increase physical activities, particularly on ships (e.g., by means of appropriate fitness equipment). An example of this is a one-year pilot project for health promotion with 730 Finnish sailors, which included information briefings on a healthy diet as well as an anti-smoking and anti-alcohol campaign. Moreover, the test persons could participate in fitness courses. Through the different interventions, alcohol consumption could be reduced, and physical fitness as well as occupational safety could be increased (Saarni et al. 2001). In addition, the injury risk of soldiers can be reduced by sufficient physical activity (Jones and Knapik 1999).

However, the comparison of studies with test persons from the overall population with studies involving military personnel is only expedient to a limited extent because it must be taken into account, among other things, that the studies on soldiers do not constitute a representative cross section of the population in most cases. What the seven studies considered frequently have in common is a high share of male test persons. The military profession is the reason for the fact that the share of women in the overall collective of the entire military personnel is mostly low, and thus the share of women in the studies also tends to be low. Therefore, the results (of these studies) can be compared with examinations on the overall population to a limited extent only. The young age structure of the military participants (mostly between 20 and 30 years) also limits the comparability of associated data with those of studies involving the overall population. Owing to regular health examinations in the military, the collective of soldiers in the above studies is selected in favor of fit, primarily healthy 
persons in the sense of the healthy worker effect (Baillargeon 2001). Thus, the comparison between soldiers and the civilian population is limited with regard to various factors, but it yields an indication for the assessment of the activity of daily life of this occupational group.

High physical fitness is very important for soldiers during day-to-day duties and also during missions abroad. Moreover, noncompliance with the physical preconditions can result in career disadvantages or exclusion from military service (Bundesministerium der Verteidigung 2009). This explains why soldiers comply with the physical activity recommendation and achieve a better physical activity behavior than the civilian population. The latter is not subject to this pressure and is thus less obliged by external factors to keep fit. This has an influence on the physical activity motivation of the individual persons.

This systematic literature review has method-related strengths and weaknesses. Owing to the systematic approach within the scope of the literature review, no essential papers will be overlooked in the databases, if they have been identified as hits by the search algorithm (Muka et al. 2020). Nevertheless, it is conceivable that papers have not been included, particularly if they were published in journals not listed in the PubMed database (Muka et al. 2020). Moreover, examinations on soldiers in particular are at times not freely accessible, which could also result in a nonconsideration of studies on this subject. As the study results were not available in both cases, it cannot be estimated to what extent these circumstances might have influenced the result of the literature review. A particular strength of this paper is the fact that, for the first time, a calculation of the average number of steps was effected, taking into account the number of test persons of all usable studies, so that the daily number of steps performed by this occupational group could be analyzed within the scope of a synopsis.

On the other hand, this paper shows the difficulty regarding comparability of the studies with each other, which is due to the different numbers of participants and the use of different pedometers of various manufacturers (Ainsworth et al. 2015; $\mathrm{Li}$ et al. 2016). However, it is particularly the measurement under different conditions, e.g., during employment on board a ship or under special military training and operational conditions, which poses a challenge for the comparison of studies. Moreover, the studies were consistently performed in different nations, which is desirable in principle, but further limits comparability due to the different activities performed during the measurements.

In summary, it could be shown by means of this literature review that soldiers performed more physical activity than the civilian population in the studies recorded and that the recommended 10,000 steps per day were slightly exceeded on average. However, the number of steps performed was very low in fields of activity with limited physical activity options, such as on board a ship. Altogether, it thus seems that additional health-promoting physical activity programs are not required for most of the soldiers, but that, in contrast, corresponding offers for physical activity alternatives, e.g., in the form of fitness equipment, are urgently required in specific task areas (e.g., on board ships).

Authors' contributions CS and SS were responsibility for the review, the screening of the articles and the summary presented. CS was a major contributor in writing the manuscript. All authors read and approved the final manuscript.

Funding Open Access funding enabled and organized by Projekt DEAL. This research did not receive any specific grant from funding agencies in the public, commercial, or not-for-profit sectors.

Availability of data and materials All data generated or analyzed in this review is included in this published article.

\section{Declarations}

Ethics Approval A vote of the ethics committee was not necessary for this systematic review.

Consent to Participate Not applicable.

Consent for Publish Not applicable.

Conflict of interest Both authors declare that they are active Bundeswehr Medical Service officers and work for the Federal Ministry of Defence and that no funding was received in the publication of this article.

Open Access This article is licensed under a Creative Commons Attribution 4.0 International License, which permits use, sharing, adaptation, distribution and reproduction in any medium or format, as long as you give appropriate credit to the original author(s) and the source, provide a link to the Creative Commons licence, and indicate if changes were made. The images or other third party material in this article are included in the article's Creative Commons licence, unless indicated otherwise in a credit line to the material. If material is not included in the article's Creative Commons licence and your intended use is not permitted by statutory regulation or exceeds the permitted use, you will need to obtain permission directly from the copyright holder. To view a copy of this licence, visit http://creativecommons.org/licenses/by/4.0/.

\section{References}

Aandstad A, Hageberg R, Holme IM, Anderssen SA (2016) Objectively measured physical activity in home guard soldiers during military service and civilian life. Military Med 181(7):693-700

Ainsworth B, Cahalin L, Buman M, Ross R (2015) The current state of physical activity assessment tools. Prog Cardiovasc Dis 57(4):387395

Althoff T, Sosič R, Hicks JL, King AC, Delp SL, Leskovec J (2017) Large-scale physical activity data reveal worldwide activity inequality. Nature 547(7663):336-339 
Baillargeon J (2001) Characteristics of the healthy worker effect. Occup Med 16(2):359-366

Brown WJ, Bauman AE, Bull F, Burton NW (2012) Development of evidence-based physical activity recommendations for adults (18 to 64 years). Report prepared for the Australian Government Department of Health. https://www.health.gov.au/resources/ publications/development-of-evidence-based-physical-activity-foradults-18-to-64-years

Bundesministerium der Verteidigung (2009) Weisung zur Ausbildung und zum Erhalt der Individuellen Grundfertigkeiten (Weisung IgF)

Choi S-W, Lee J-H, Jang Y-K, Kim J-R (2010) Assessment of ambulatory activity in the Republic of Korea navy submarine crew. Undersea Hyperbaric Med: J Undersea Hyperbaric Med Soc Inc 37(6):413-417

Costa FF, Montenegro VB, Lopes TJ, Costa EC (2011) Combination of risk factors for metabolic syndrome in the military personnel of the Brazilian Navy. Arq Bras Cardiol 97(6):485-492

Diaz KM, Howard VJ, Hutto B, Colabianchi N, Vena JE, Safford MM, Blair SN, Hooker SP (2017) Patterns of sedentary behavior and mortality in U.S. middle-aged and older adults: a National Cohort Study. Ann Intern Med 167(7):465-475

Froböse I, Biallas B, Wallmann-Sperlich B (2018) Der DKV-Report 2018: Wie gesund lebt Deutschland? https://www.bisp-surf.de/ Record/PU201807005420. Accessed 29 November 2018

Gregg MA, Jankosky CJ (2012) Physical readiness and obesity among male U.S. Navy personnel with limited exercise availability while at sea. Military Med 177(11):1302-7

Guthold R, Stevens GA, Riley LM, Bull FC (2018) Worldwide trends in insufficient physical activity from 2001 to 2016 : a pooled analysis of 358 population-based surveys with 1.9 million participants. Lancet Glob Health 6(10):e1077-e1086

Jones BH, Knapik JJ (1999) Physical training and exercise-related injuries. Surveillance, research and injury prevention in military populations. Sports Med 27(2):111-125

Kinnunen H, Tanskanen M, Kyröläinen H, Westerterp KR (2012) Wristworn accelerometers in assessment of energy expenditure during intensive training. Physiol Meas 33(11):1841-1854

Li RT, Kling SR, Salata MJ, Cupp SA, Sheehan J, Voos JE (2016) Wearable performance devices in sports medicine. Sports Health 8(1):74-78

Muka T, Glisic M, Milic J, Verhoog S, Bohlius J, Bramer W, Chowdhury R, Franco OH (2020) A 24-step guide on how to design, conduct, and successfully publish a systematic review and meta-analysis in medical research. Eur J Epidemiol 35(1):49-60

Nykanen T, Pihlainen K, Santtila M, Vasankari T, Fogelholm M, Kyrolainen H (2019) Diet macronutrient composition, physical activity, and body composition in soldiers during 6 months deployment. Mil Med 184(3-4):e231-e237

Perk J, de Backer G, Gohlke H, Graham I, Reiner Z, Verschuren M, Albus C, Benlian P, Boysen G, Cifkova R, Deaton C, Ebrahim S, Fisher M, Germano G, Hobbs R, Hoes A, Karadeniz S, Mezzani A, Prescott E, Ryden L, Scherer M, Syvanne M, Scholte Op Reimer WJM, Vrints C, Wood D, Zamorano JL, Zannad F, Cooney MT, Bax J, Baumgartner H, Ceconi C, Dean V, Fagard R, FunckBrentano C, Hasdai D, Kirchhof P, Knuuti J, Kolh P, McDonagh T, Moulin C, Popescu BA, Sechtem U, Sirnes PA, Tendera M, Torbicki A, Vahanian A, Windecker S, Aboyans V, Ezquerra EA, Baigent C, Brotons C, Burell G, Ceriello A, de Sutter J, Deckers J, Del Prato S, Diener H-C, Fitzsimons D, Fras Z, Hambrecht R,
Jankowski P, Keil U, Kirby M, Larsen ML, Mancia G, Manolis AJ, McMurray J, Pajak A, Parkhomenko A, Rallidis L, Rigo F, Rocha E, Ruilope LM, van der Velde E, Vanuzzo D, Viigimaa M, Volpe M, Wiklund O, Wolpert C (2012) European guidelines on cardiovascular disease prevention in clinical practice (version 2012): the fifth joint task force of the European Society of Cardiology and Other Societies on cardiovascular disease prevention in clinical practice (constituted by representatives of nine societies and by invited experts) * developed with the special contribution of the European Association for Cardiovascular Prevention \& rehabilitation (EACPR). Eur Heart J 33(13): 1635-1701

Pfeifer K, Rütten A (2017) National Recommendations for physical activity and physical activity promotion. Gesundheitswesen (Bundesverband der Arzte des Offentlichen Gesundheitsdienstes (Germany)) 79(S 01):S2-S3

Saarni H, Laine M, Niemi L, Pentti J (2001) Health promotion in the Finnish shipping industry. Int Marit Health 52(1-4):44-58

Sammito S, Mayer-Falcke A (2017) F I-S-3 - Soldat. In: Letzel S, Nowak D (eds.) Handbuch der Arbeitsmedizin. Ecomed Verlag, Hamburg, pp 1-20

Sammito S, Schlattmann A, Felfe J, Renner K-H, Stein M, Winkler G, Krauth C, Latza U, Densow D, Erley OM, Rose DM (2015) Occupational health management in the ministry of defense - scientific steering of a comprehensive projekt. Wehrmed Mschr 59(8): 230-235

Schulze C, Lindner T, Goethel P, Müller M, Kundt G, Stoll R, Mittelmeier W, Bader R (2015) Evaluation of the physical activity of German soldiers depending on rank, term of enlistment, and task area. Mil Med 180(5):518-523

Scott EJ, Eves FF, French DP, Hoppé R (2007) The theory of planned behaviour predicts self-reports of walking, but does not predict step count. Br J Health Psychol 12(Pt 4):601-620

Staudter M, Dramiga S, Webb L, Hernandez D, Cole R (2011) Effectiveness of pedometer use in motivating active duty and other military healthcare beneficiaries to walk more. U.S. Army Med Dep J Jul-Sept:108-119

Tharion WJ, Yokota M, Buller MJ, DeLany JP, Hoyt RW (2004) Total energy expenditure estimated using a foot-contact pedometer. Med Sci Monitor: Intl Med J Exp Clin Res 10(9):CR504-CR509

Tudor-Locke C, Craig CL, Brown WJ, Clemes SA, de Cocker K, GilesCorti B, Hatano Y, Inoue S, Matsudo SM, Mutrie N, Oppert J-M, Rowe DA, Schmidt MD, Schofield GM, Spence JC, Teixeira PJ, Tully MA, Blair SN (2011) How many steps/day are enough? For adults. Intl J Behavior Nutrition Phys Activ 8:79

Voermans S, Hombrecher M, Borgerding K, Wolters S, Ahlers G, Helbig B (2016) Beweg dich, Deutschland!: TK-Bewegungsstudie 2016. https://www.bisp-surf.de/Record/PU201606003216. Accessed 29 November 2018

Warburton DE, Charlesworth S, Ivey A, Nettlefold L, Bredin SD (2010) A systematic review of the evidence for Canada's physical activity guidelines for adults. Int J Behav Nutr Phys Act 39(7)

WHO (2010) Global recommendations on physical activity for health. https://www.who.int/publications/i/item/9789241599979

Wyss T, Scheffler J, Mäder U (2012) Ambulatory physical activity in Swiss Army recruits. Int J Sports Med 33(9):716-722

Publisher's note Springer Nature remains neutral with regard to jurisdictional claims in published maps and institutional affiliations. 